\title{
Calculations of the rigidity and the strength of concrete filled steel deck diaphragms
}

\author{
Oleg Efimov ${ }^{1}$, Linur Gimranov ${ }^{10000-0003-1728-1825]}$, and Alsou Fattakhova $^{1^{*}}$ \\ ${ }^{1}$ Kazan State University of Architecture and Engineering, 420043 Kazan, Russia
}

\begin{abstract}
Calculations of horizontal loads such as wind are required even for low-rise buildings. With stores number increasing their influence increases. The horizontal loads are perceived by the flooring discs. Steelreinforced concrete floors with profiled decking are most often used in steel frame buildings. Floor slabs and frame's joint work is ensured by shear studs. The article discusses a shear studs' stress determining method from horizontal load. There are different slab supporting variants: slap supported on two sides and along slab's perimeter. The goal was to determine shear stress in each flexible stop. The tasks were solved by calculating and by computing. Then the results were compared. Therefore, the resulting formula allows determining shear stresses not only in square slab but in rectangular ones too. Shear stress knowledge in the studs allows to determinate frames' displacements by horizontal loads. Frame displaces relative to the floor slab due to studs shear and flexibility. The derived displacements determining formula takes into account shear deformations and anchor compliance in different directions. Herewithin the article, proposed displacements formula is not checked, but only the components determining a method is proposed.
\end{abstract}

Keywords. Steel-reinforced concrete slab, profiled flooring, horizontal loads, shear studs, group of bolts.

\section{Introduction}

Currently, buildings with a metal frame are becoming more common. Most of buildings and structures have a small storeys number, however, even when such buildings frame calculating, horizontal loads are required, for example, wind. Horizontal loads damage effect increases in higher structures. So for multi-storey civil buildings from metal frames, wind load increases so much that snow load can be neglected. This indicates the frame's horizontal loads action stiffness studying importance.

Russian regulatory documents norms displacements only from vertical loads. Almost all multi-storey buildings in US are built of metal frames, however, despite such structure's widespread prevalence, the displacement issues from horizontal loads are only superficially explored [1-3]. The horizontal ones are perceived by the overlapping discs. The most common solution is a steel-reinforced concrete slab using profiled decking. The reinforced concrete slab and the frame's joint work is ensured by shear studs. Studs are anchored into

${ }^{*}$ Corresponding author: fattakhova.alsou@yandex.ru 
the slab, pass through the profiled sheet and are attached to the floor beams. The stiffness of the concrete slab and cell beams is so high that displacements are possible only due to studs.

There are no calculations of flexible stops from the action of horizontal loads in SP 266.13258000-2016 on steel-reinforced concrete structures. The stud's cross section is selected according to the vertical loads forces. And the setting step is regulated by the concrete's complex compression and the stud's and the slab's joint work [4-6].

In the foreign literature there is combined floors' studs calculating section taking into account the horizontal loads action [7, 8]. Foreign manufacturers have their own technical specifications based on their countries scientists' researches. However, the normative documents used abroad differ from the domestic ones, so manufacturers have to prove the certain design solutions using admissibility.

In light of this, frame's horizontal loads displacement determination task was set. Namely, a method is required that makes it possible to assess the frame rigidity, without going into each element deformability calculating details, but operating only on the applied load.

Shear studs - structural elements that ensure the frame rigidity and work for shear forces and some compliance. Therefore, stud's shear forces determination is necessary, and then displacements determination becomes possible only taking into account the stud's flexibility.

A square-shaped slab in the plan was considered, studs fixed the beam cell on two sides and along the perimeter. In considered task studs were small rods of circular cross-section with a 6 to $25 \mathrm{~mm}$ diameter with a head at one end, since this is the simplest constructive solution used in combined floors.

\section{Materials and methods}

The engineering task is conditionally divided into two stages: to determine the forces in the studs from the acting load, then to determine the frame (the beam cell) relative to the slab displacements. When solving the problem, it was assumed that frame and slab rigidity is infinitely large and is not deformed at all. The design scheme is shown in Fig. 1a. The axb frame is fixed vertically and horizontally. Studs are conventionally shown, located along the longitudinal beams. From the load $F$ action frame shifts by $\Delta$, and shear forces $Q_{x}$ and $Q_{y}$ appear in the studs.

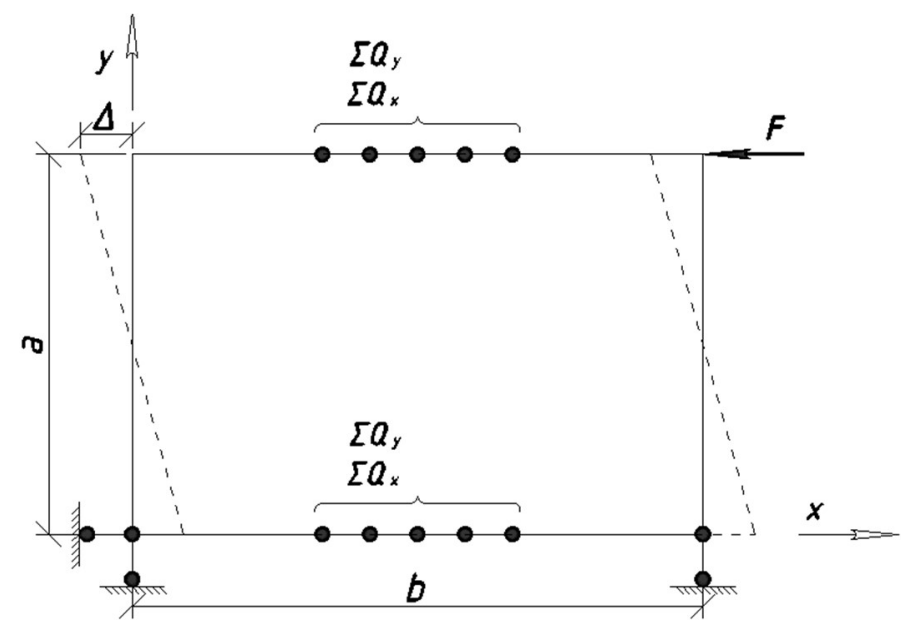

Fig. 1. Design scheme of the frame.

By breaking the frame into individual members, you can determine the support reactions and forces in the members using the moment equilibrium equation. Next, we plot the internal forces diagrams for the longitudinal beam to which the load is applied. 


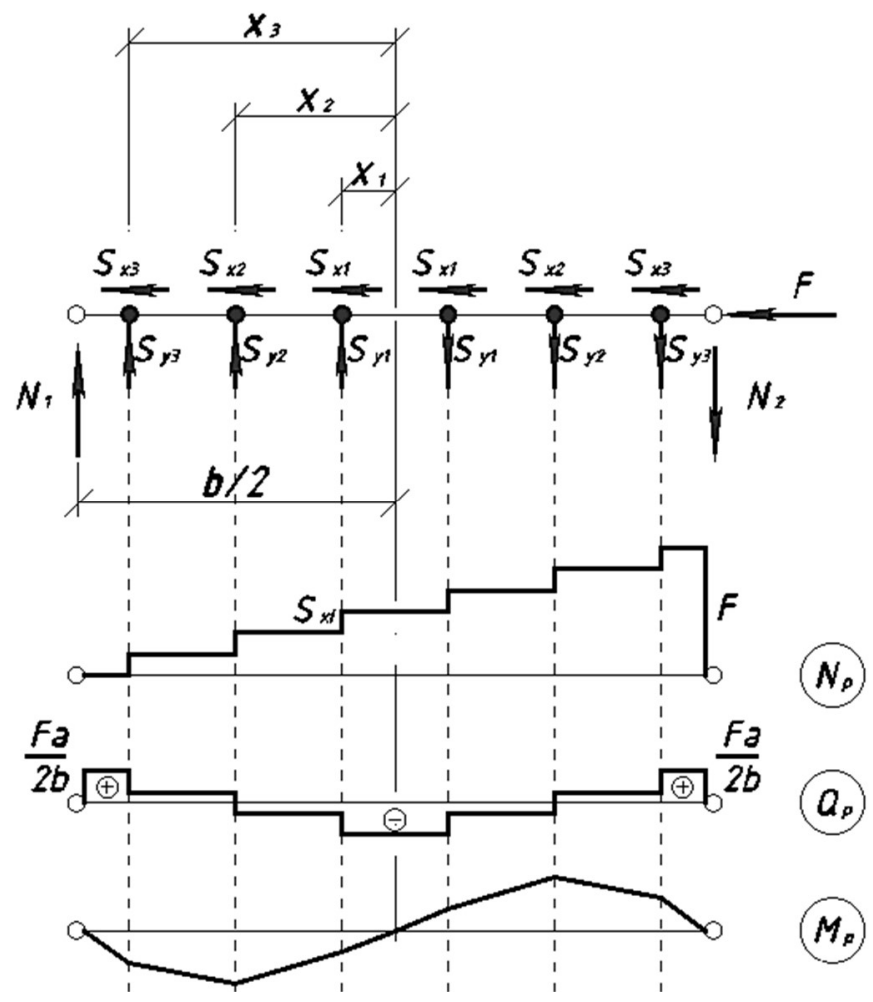

Fig. 2. Diagrams of internal forces in the frame longitudinal beam.

According to structural requirements, flexible stops are placed symmetrically along the floor beams, therefore, it is sufficient to consider the equilibrium equations for half of the frame. The force in each flexible stop will be denoted by $S_{x i}$ and $S_{y i}$. Let us determine what the vertical component $S_{y i}$ is equal to according to the moment equilibrium equation (1). This requires additional equations (2):

$$
\begin{gathered}
\sum_{i=1}^{n_{b}} S_{y i} x_{i}=\frac{F a}{4}, \\
\frac{S_{y i}}{S_{y 1}}=\frac{x_{i}}{x_{1}} \\
S_{y i}=\frac{\frac{F a}{4} x_{i}}{\sum x_{i}^{2}} .
\end{gathered}
$$

To determine the horizontal component $S_{x i}$, it is necessary to divide the actual load by the number of stops in the beam $n_{b}$ :

$$
S_{x i}=\frac{F}{n_{b}} .
$$

Now we will consider the same problem, but with fixing the slab along the contour. The design scheme is shown in Fig. 3.

We will assume that each anchor is conventionally divided into two parts: a part that receives shear before the load is applied and a part that balances the system. We denote the shear forces by $S_{x 1}$, and the balancing system by $S_{x 2}$. After applying the load, the shear forces became equal to $S_{x 1}$.

The problem was solved by the work relaxation, for this the given system was dissected along flexible stops. A single moment was applied to the main system. 


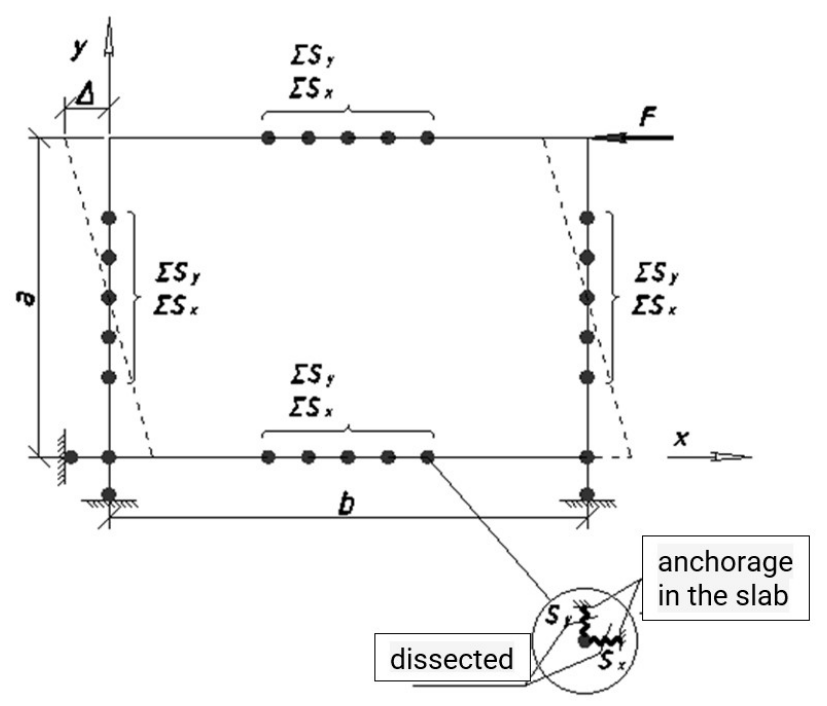

Fig. 3. Design scheme of the frame.

The canonical equation is compiled from the application to the main system of the unit moment $\gamma_{11} M+\gamma_{i p}=0$.

According to the mechanics rules, the shearing force value is determined as:

$$
Q=\frac{2 \cdot x_{\mathrm{K}}}{\sum x_{i}^{2}}
$$

where $x_{\kappa}$ - the distance from the extreme stud gravity centre to the beam's middle; $x_{i}$ - distance from the $i$-th stud gravity centre to the beam middle.

Then the rotation angle from the unit moment will be:

where $a$-slab width;

$$
\gamma_{11}=4\left(\frac{2 \cdot x_{\mathrm{\kappa}}}{\sum x_{i}^{2} a t G}\right),
$$

$t$ - slab reduced thickness;

$G$ - slab reduced shear modulus.

The rotation angle from the applied moment is:

$$
\gamma_{i p}=\frac{\sum S_{x 1}+\sum S_{y 1}}{a t G}
$$

As a canonical equation solving result, the moment was determined:

$$
M=-\frac{\left(\sum S_{x 1}+\sum S_{y 1}\right) \sum x_{i}^{2}}{8 x_{\mathrm{K}}}
$$

Now, knowing what the moment in the frame is, it is possible to determine the forces that balance the system:

$$
\begin{aligned}
S_{x 2 i} & =\frac{M_{1} y_{i}}{\sum y_{i}^{2}}, \\
S_{y 2 i} & =\frac{M_{1} x_{i}}{\sum x_{i}^{2}}
\end{aligned}
$$

and the forces resulting from the application of the load $F$ :

$$
\begin{aligned}
& S_{x 1 i}^{\prime}=S_{x 1 i}+\frac{4 M}{a}, \\
& S_{y 1 i}^{\prime}=S_{y 1 i}+\frac{4 M}{b} .
\end{aligned}
$$

The forces $S_{x i}$ and $S_{y i}$ are determined by analogy with the previous task and by the forces in the beams. For horizontal beams: 
and for vertical beams

$$
\begin{gathered}
S_{x i}=\frac{F}{n_{b}}, \\
S_{y i}=\frac{\frac{F a}{4} x_{i}}{\sum x_{i}^{2}}
\end{gathered}
$$

$$
\begin{array}{r}
S_{x i}=\frac{\frac{F b}{4} y_{i}}{\sum y_{i}^{2}}, \\
S_{y i}=\frac{F a}{2 b n_{a}} .
\end{array}
$$

Before proceeding to the second part of the problem, calculations should be proved. If these solutions are correct two different methods results will be closely the same. Forces in the studs were computed by the finite element method implemented on the PC Lira-CAD.

In a square slab with dimensions of $0.6 \times 0.6 \mathrm{~m}$, the stud bolts are supplied with a step of $10 \mathrm{~cm}$. In the software package, it is necessary to indicate the stiffness, previously a number of tasks were considered, in which combined floor elements geometric characteristics were refined. Therefore, in the task, the flooring beams are made of 60B2 I-beams, the stud bolts are taken with a $16 \mathrm{~mm}$ section. Reinforced concrete slab with fixed formwork made of profiled sheet is modelled by reduced thickness plates equal to $13 \mathrm{~mm}$, which corresponds to an $80 \mathrm{~mm}$ height profiled decking overlap and $70 \mathrm{~mm}$ reinforced concrete shelf. The characteristics of the material are specified as for concrete B20. Fig. 4 shows the design diagram of the overlap disk after the calculation, the deformed diagram is shown in purple.

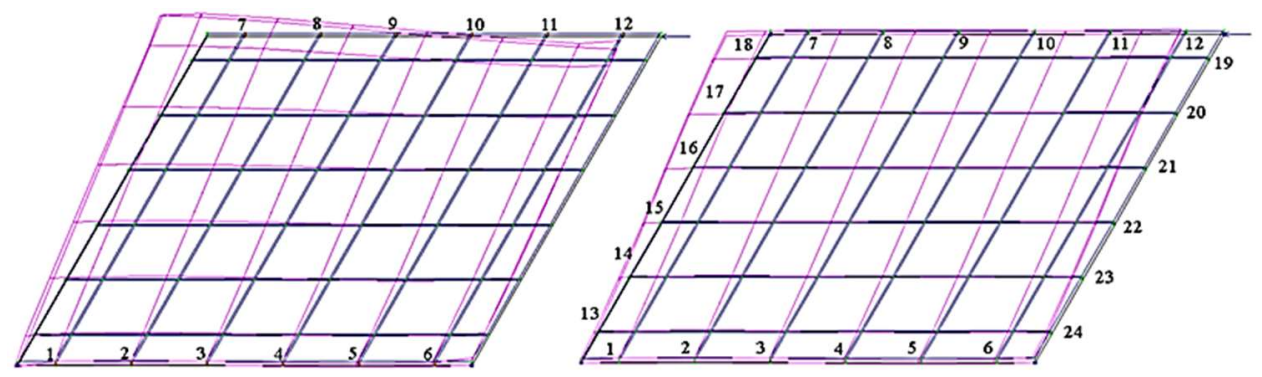

Fig. 4. Design scheme of a slab with numbering of bolts.

The calculations and computing results convergence made it possible to move towards the final goal: the displacements determination. The movement is made up of studs' shear and flexibility (5):

$$
\Delta=\sum \int_{0}^{b} \frac{N_{p} \bar{N}}{E A_{x}} d l+\sum \int_{0}^{b} \frac{N_{p} \bar{N}}{E A_{y}} d l+\sum \int_{0}^{b} \frac{M_{p} \bar{M}}{E J_{z}} d l+2 n_{b} S_{i x} D_{x}+2 n_{b} S_{i y} D_{y},
$$

$N_{p}, M_{p}$ - the effort value from applied load;

$N^{\prime}, M^{\prime}$ - the effort value from a single load;

$D_{x}, D_{y}$ - compliance value determined from the graphs.

Considering that the cargo and unit diagrams are similar, formula (5) is transformed into (6).

$$
\Delta=\frac{2 F a i^{2}}{3 E A_{x} n_{b}^{2}}+\frac{F a^{5}}{24 n_{b}^{2} b^{2} E J_{x}}+2 n_{b} S_{i x} D_{x}+2 n_{b} S_{i y} D_{y}
$$

\section{Results}

Here we present numerical experiments results and clearly demonstrate the methods convergence. 
A load of 50kN was applied; the resulting shear forces in the bolts are shown in tables 1 and 2 to support the slab on two sides and along the contour, respectively. Bolt numbering is shown in Fig. 4. Since both tasks are symmetrical, that is, the forces in bolts 1, 6, 7 and 12 are equal (Fig. 5a), and for the case in Fig. 5b, and also shear forces at 13, 18, 19 and 24, then the tables show the average results of the day of the quarter of the frame. For calculations and computing results comparing convenience the forces in the corresponding flexible stops are written under each other in one column. In calculation, it was assumed that the shear forces would be equal in pairs, so only half of the frame was considered. At this stage, it was required to check the shear forces determining solutions convergence.

Table 1. Shear forces in flexible stops.

\begin{tabular}{|c|c|c|c|c|c|c|}
\hline Number of studs & $1-12$ & $2-11$ & $3-10$ & $4-9$ & $5-8$ & $6-7$ \\
\hline \multirow{2}{*}{$S_{x i}$} & 0.901 & 2.163 & 2.4 & 2.318 & 1.897 & 0.484 \\
\cline { 2 - 7 } & 0.932 & 2.141 & 2.39 & 2.308 & 1.876 & 0.516 \\
\hline Difference, \% & 3.3 & 1 & 0.4 & 0.4 & 1.1 & 6.2 \\
\hline \multirow{2}{*}{$S_{y i}$} & 4.676 & 2.887 & 0.806 & 0.916 & 2.952 & 4.446 \\
\cline { 2 - 7 } & 4.153 & 2.507 & 0.686 & 0.796 & 2.572 & 3.923 \\
\hline Difference, \% & 11.2 & 13.2 & 14.9 & 13.1 & 12.9 & 11.8 \\
\hline
\end{tabular}

Table 2. Shear forces in flexible stops.

\begin{tabular}{|c|c|c|c|c|c|c|}
\hline Number of studs & $1-12$ & $2-11$ & $3-10$ & $4-9$ & $5-8$ & $6-7$ \\
\hline \multirow{2}{*}{$S_{x i}$} & 0.901 & 2.163 & 2.4 & 2.318 & 1.897 & 0.484 \\
\cline { 2 - 7 } & 0.932 & 2.141 & 2.39 & 2.308 & 1.876 & 0.516 \\
\hline Difference, \% & 3.3 & 1 & 0.4 & 0.4 & 1.1 & 6.2 \\
\hline \multirow{2}{*}{$S_{y i}$} & 4.676 & 2.887 & 0.806 & 0.916 & 2.952 & 4.446 \\
\cline { 2 - 7 } & 4.153 & 2.507 & 0.686 & 0.796 & 2.572 & 3.923 \\
\hline Difference, \% & 11.2 & 13.2 & 14.9 & 13.1 & 12.9 & 11.8 \\
\hline
\end{tabular}

\section{Discussion}

The problem of determining displacements of a floor composite steel concrete diaphragm comprised of a steel-reinforced concrete slab and a specialised steel deck supported by a beam frame, has been solved. To determine the displacements, it was necessary to determine the forces in the shear studs.

Force actions were determined by calculations and numerical methods. The validation of devised methods was conducted on the square shaped slab connected to the beam frame with shear studs. The analytical calculation was compared with the results obtained in the computing using the software package. The reliability of the results obtained by the numerical experiment was described in previously published articles $[9,10]$.

As a result, it was concluded that the proposed manual calculation methods can be used to calculate the shear forces to determine the frame displacements. It should be noted that the formulas were derived for a rectangular in plan slab; therefore, the proposed method can be used to determine the forces for any size and with any aspect ratio slabs.

The methods convergence comparison was checked on a small sample with a small number of studs; earlier [11] a method based on the bolts group calculating [12] analogy was proposed. However, the numerical experiment result showed that with a such comparison, convergence of force actions in shear studs will be only for the first 3-5 studs due to the diaphragm sample size and quantaty of flexible shear connectors. Therefore, the more accurately shear forces in the corner studs are determined, the more convergence the method will have when comparing the calculating and computing results.

To determine the frame movement by the proposed method, it is necessary to know the longitudinal and shearing forces diagrams in the cell beams, as well as the shear studs 
flexibility. Compliance is determined for each flexible stop design separately. Manufacturers devised special tables and graphs based on test results for the each frequently occurring cases of design solution. For example, in [13-16], graphs are shown for different stud diameters, depending on the plate dimensions, stops setting step.

Within the study's framework, the task was set: to determine shear forces in flexible stops, and it was successfully solved. As for the displacements, here is a formula for their determination. The problem lies in the obtained result reliability checking; it is necessary to think over a way to check the proposed formula values reliability. These are the subsequent research tasks.

\section{Conclusion}

The main work results and the drawn conclusions are:

- horizontal loads displacements must be taken into account;

- these movements aren't normed by domestic and foreign design standards;

- the framework moves relative to the overlap disc due to the studs shear and their flexibility;

- shear forces have been determined to support the slab on both sides and along the contour;

- the proposed method derived formulas make it possible to determine the forces for square and rectangular slabs;

- comparison of the results with a numerical experiment made it possible to draw a conclusion about the method's applicability;

- the formula has been proposed for determining the displacements, which takes into account both shear forces and the studs' flexibility.

\section{References}

1. L. Luttrell, J. Mattingly, W. Schultz. Sputo Diaphragm Design Manual, Steel Deck Institute $4^{\text {th }}$ Ed. T., 405 (2015).

2. Reda Farag. Reliability assessment of wall-frame structures, Ain Shams Engineering Journal 6 Iss. 3, 725-733 (2015). DOI: 10.1016/j.asej.2015.01.001.

3. S. Pala, G. Özmen. Lateral load analysis of multi-storey structures considering axial deformations, Computers \& Structures 34 Iss. 4, 577-583 (1990). DOI: 10.1016/00457949(90)90235-T.

4. F.S. Zamaliev. To the calculation of steelreinforced concrete floors with profiled steel flooring, Izvestiya KGASU 3 (37), 129-134 (2016).

5. E.L. Ayrumyan, N.I. Kamenshchikov, I.A. Rumyantseva. Osobennosti rascheta monolitnykh plit stalezhelezobetonnykh pokrytiy po profilirovannomu stal'nomu nastilu. Promyshlennoye i grazhdanskoye stroitel'stvo 9, 21-26 (2015).

6. F.S. Zamaliev. K raschetu ankernykh svyazey stalezhelezobetonnykh konstruktsiy Izvestiya KGASU 3 (49), 87-94 (2019).

7. R.P. Jonson. Designer's guide to Eurocode 4: Design of composite steel and concrete structures EN 1994-1-1 (transl. from engl.). Moscow, MGSU, 412 (2013).

8. V.O. Almazov, S.N. Harutyunyan. Design of Composite Reinforced Concrete Slabs according to Eurocode 4 and Russian Recommendations, Vestnik MGSU 8, 51-65 (2015). DOI: 10.22227/1997-0935.2015.8.51-65.

9. Linur Gimranov, Alsou Fattakhova. Shear stops forces distribution analysis in combined floors of multi-storey buildings, IOP Conf. Ser.: Mater. Sci. Eng. 890, 012080 (2020). DOI: 10.1088/1757-899X/890/1/012080. 
10. A.I. Fattakhova. Impact of horizontal loads on the work of stud bolts in combined floor slabs, Vestnik MGSU 15 (1), 31-42 (2020). DOI: 10.22227/1997-0935.2020.1.31-42.

11. A.I. Fattakhova. Multi-storey buildings combined floors with different aspect ratios shear stops forces distribution analysis, Izvestiya vuzov. Stroitel'stvo 1, (2020). DOI: 10.32683/0536-1052-2020-733-1-46-56.

12. T. Bart Quimby, P.E., Ph.D., F. Asce. A Beginner's Guide to the Steel Construction Manual An introduction to designing steel structures using the AISC Steel Construction Manual, $15^{\text {th }}$ edition. Alaska, 53 (2017).

13. Dung-Myau Lue, Cheng-Yen Liao, Chien-Chien Chang, Wei-Ting Hsu. Improved analysis of bolted shear connection under eccentric loads, Journal of Marine Science and Technology 25 4, 373-382 (2017). DOI: 10.6119/JMST-017-0223-1.

14. Tom Molkens, Jelena Dobrić, Barbara Rossi. Shear resistance of headed shear studs welded on welded plates in composite floors. DOI: 10.1016/j.engstruct.2019.109412.

15. Y. Ling, Z. Zheng, T.Y. Yang, H. Ma. Behaviour and modeling of the bearing capacity of shear stud connectors, International Journal of Steel Structures 19 2, 650-659 (2019). DOI: 10.1007/s13296-018-0154-3.

16. H.B. Shim, J.H. Lee. Shear force of headed shear studs, high-strength shear studs and steel plate embedded in concrete: an experimental study, Material Research Innovations 19 (S8), S8-145-S8-148. DOI: 10.1179/1432891715Z.0000000001645. 